\title{
Estimation of economic burden of preterm and premature births in Iran
}

\author{
Nahal Ahmadzadeh ${ }^{1}$, Aziz Rezapour ${ }^{1,2}$, Zahra Ghanavatinejad ${ }^{1}$, Mojtaba Nouhi $^{1}$, Somayeh \\ Karimi ${ }^{1}$,Alireza Saravani ${ }^{1}$, Ahmadreza Nasre Tahooneh ${ }^{1}$, Reza Jahangiri ${ }^{1 *}$ \\ Received: 16 Dec 2016 \\ Published: 13 Dec 2017
}

\begin{abstract}
Background: Tremendous difficulties are imposed on families with preterm and premature babies, both at birth and during their lifetime. The present study aimed at evaluating the potential economic impact of preterm and premature birth in Iran.

Methods: In this descriptive cross-sectional study (2014-2015), we studied preterm and premature newborns, who have been subjected to hospitalization in Ali-Asghar hospital. We followed social perspective to estimate the economic consequences of preterm and premature birth in 3 categories of direct medical, direct non-medical, and indirect costs. Required data were collected from documents in the NICU, and studying medical records, and interviewing their parents. Data were analyzed by Microsoft Excel.

Results: Direct medical, direct non-medical and indirect affairs were $84 \%, 6 \%$, and $10 \%$ of the total cost, respectively. The estimated social costs were $373,529,189 ; 508,774,181$; and 529, 481, 996 US dollars (according to their corresponding incidence of 5.8\%, 7.9\%, and $9.9 \%$ ). We also found that $75 \%$ of the direct medical costs of initial hospitalization were due to intensive care beds.

Conclusion: The economic burden of preterm and premature birth in Iran is considerable and to decrease the costs, it is necessary to implement preventive programs for preterm and premature newborns and to provide management care and support for families dealing with this problem.
\end{abstract}

Keywords: Premature and preterm infants, Neonatal Intensive Care Unit (NICU), Economic burden

Copyright $\odot$ Iran University of Medical Sciences

Cite this article as: Rezapour A, Ghanavatinejad Z, Nouhi M, Karimi S, Saravani A, Nasre Tahooneh A, Jahangiri R. Estimation of economic burden of preterm and premature births in Iran. Med J Islam Repub Iran. 2017 (13 Dec);31:78. https://doi.org/10.14196/mjiri.31.78

\section{Introduction}

Prematurity is characterized by gestational age and is defined as childbirth occurring at less than 37 weeks(1). The rate of preterm births ranges from $12 \%$ to $13 \%$ in the U.S. and $5 \%$ to $9 \%$ in other developed countries $(2,3)$; and in Iran, it ranges from $5.5 \%$ in Shiraz to $8.21 \%$ in Arak (1). Depending on the condition and age at birth and birth weight, the premature and preterm neonates might suffer from a spectrum of defects. In general, preterm newborns have more medical issues and hospitalization costs than the full term $(4,5)$. They are also prone to a broad range of adverse consequences including chronic lung disease, severe brain injury, retinopathy of prematurity, and neonatal sepsis(6). Compared to those with normal births, premature

Corresponding author: Reza Jahangiri, reza.jahan67@gmail.com

1. Health Management and Economics Research Center, Iran University of Medical Sciences, Tehran, Iran.

2. Department of Health Economics, School of Health Management and Information Sciences, Iran University of Medical Sciences, Tehran, Iran. newborns are more likely to suffer from temperature instability, respiratory distress, apnea, hypoglycemia, seizures, jaundice, kernicterus, feeding difficulties, periventricular leukomalacia, and rehospitalizations (7-9).

Although advances in technology and intervention approaches during the past two decades have led to substantial improvements in the antenatal and infant cares and survival of even the most premature newborns $(10,11)$, there is still a great concern about costs of hospitalization and intensive care for prematurity $(11,12)$. Health systems not only play a critical and important role in improving health, but also are responsible to protect individuals against the financial costs of illnesses and diseases (13). Regarding the fact that financial management is one of the basic principles in the

$\uparrow$ What is "already known" in this topic:

Prematurity is a term coined to refer to birth at less than 37 weeks of gestation. Preterm birth may lead to mortality and is the most common reason for neonatal hospitalization.

$\rightarrow$ What this article adds:

Our study estimated the medical and non-medical costs of hospitalization in premature infants. In this study, we found that most of the economic burden of prematurity was due to direct medical costs. 
health sector, providing and managing financial resources is critical (14). Studies have shown increases in hospitalization costs during the first year of life for the infants suffering from some early defects such as bronchopulmonary dysplasia and intraventricular hemorrhage $(15,16)$. In studies on the clinical consequences of children under one-yearold with prematurity (born between 35 and 36 weeks of gestation), some investigators found more clinical problems and costs of hospitalization for the premature newborns than full term babies (10). Premature birth is also a strong predictor of the amount of money spent for hospital services by an individual in the first 5 years of life (17). Thus, beyond its large extent of socioeconomic impact on families, prematurity causes wide economical and humanoid consumption(1). Thus, it is highly important that stakeholders gain knowledge about different categories of domestic and national initial hospitalization costs (ie, age) to be able to match their health care policies.

This study was conducted to assess the costs of initial hospitalization, as the most expensive phase of intensive care (18), of premature and preterm neonates in Iran. This is vitally important as it may help the policy-makers to decide on new policies based on the measured facet of care, and hence, upgrade their strategies in consuming the financial and humanoid resources to provide better services. Also, it might help to gain the stakeholders' attention to the importance of prevention strategies.

\section{Methods}

All the preterm and premature neonates, who have been born and subjected to initial hospitalization in the NICU section of Ali-Asghar hospital in Tehran during a year (referred from the first to the last day of the year 2014-2015; $\mathrm{n}=116$ ), were included in this cross-sectional study. To assess the economic burden of these cases and to extend the results of this study to the Iranian population, a social approach was applied. Direct medical costs, which included the costs of visit and consultation, medicines, diagnostic tests, surgery, medical devices, accommodation, and hospital bed, were collected from the medical records of the neonates with predesigned forms. We used the WHO's guidance (19) to measure the costs of the cases within different age groups. Accordingly, 5.2\%, 10.4\%, and $83.4 \%$ of the cases were, respectively, attributed to age groups of $<28$, $28-<32$, and $>32$ weeks of gestation. To obtain an assessment of the average cost per neonate in the private hospitals, the average cost of public hospitals was multiplied to the tariff difference between public and private hospitals (2.32) (20). Because $15 \%$ and $85 \%$ of NICU beds are, respectively, ascribed to private and public hospitals (20), distribution of the premature neonates receiving benefits from either hospital was accordingly considered as $15 \%$ and $85 \%$.

The direct non-medical costs were measured by conducting telephone interviews with parents. We asked the parents about their expenses on travelling, accommodation of the parent, and their entourage at the time of early hospitalization.

To measure the indirect costs, we applied the human capital approach, taking into account the estimated costs of parents and other family members' (entourage) absence from their works. Notably, informal caretaking costs were not included as part of the indirect costs. For those families/family members, who were not willing to give information about their income and also the housekeeping wives, we considered the lowest wages issued by Department of Labor in the same year (2014-2015) as their income (21).

To estimate the incidence of premature and preterm birth in Iran, we used the factsheet issues by WHO, which estimated that the incidence of premature newborns in Iran was $7.9 \%(5.8-9.9 \%$; 95\% CI) of all births (22). This statistic is consistent with some other reports from Iran (2326). The total births rate in Iran in the same year was obtained from the website of Department of Statistics of Iran. Therefore, direct medical costs were estimated based on different incidence rates of $5.8 \%, 7.9 \%$, and $9.9 \%$. The data were analyzed by Microsoft Excel.

\section{Results}

In this study, 116 premature and preterm neonates, who were subjected to initial hospitalization in the NICU section of Ali-Asghar hospital in Tehran, were included. More than half of the cases $(54.7 \%)$ were female and more than half $(61.2 \%)$ of the births were from 32 to less than 37 weeks of gestation, and on average they had 22.1 days of hospitalization (Table 1). Only $8.6 \%$ of the newborns had normal weight at birth (Table 1).

We found that on average, $75 \%$ of the direct medical costs were due to length of stay in special ward, followed by $8 \%$ and $6 \%$ for medicine and diagnostic tests, respectively. The least costs (with only $1 \%$ of the costs) belonged to physician visit, consultation, and surgery (Fig. 1).

Neonates with 28 weeks gestational age had the most and

\begin{tabular}{|c|c|c|c|c|c|c|c|}
\hline Variable & & $\begin{array}{c}\text { Fre- } \\
\text { quency } \\
\text { (No.) }\end{array}$ & $\begin{array}{c}\text { Frequency } \\
(\%)\end{array}$ & Mean & $\begin{array}{c}\text { Standard } \\
\text { Deviation }\end{array}$ & Least & Most \\
\hline \multirow[t]{4}{*}{ Gender } & Male & 53 & 45.7 & $*$ & $*$ & $*$ & * \\
\hline & Female & 63 & 54.3 & & & & \\
\hline & Normal & 10 & 8.6 & 1667.3 & 547.4 & 680 & 3030 \\
\hline & LBW & 57 & 49.1 & & & & \\
\hline Birth Weight & VLBW & 38 & 32.8 & & & & \\
\hline (gr) & ELBW & 11 & 9.5 & & & & \\
\hline Gestational Age & extremely preterm (<28 weeks) & 13 & 11.2 & 31.87 & 0.78 & 26 & 37 \\
\hline \multirow[t]{2}{*}{ (Week) } & very preterm $(28$ to $<32$ weeks $)$ & 32 & 27.6 & & & & \\
\hline & Moderate to late preterm ( 32 to $<37$ weeks). & 71 & 61.2 & & & & \\
\hline $\begin{array}{l}\text { Hospitalization } \\
\text { (Day) }\end{array}$ & & $*$ & $*$ & 22.1 & 19.16 & 1 & 107 \\
\hline
\end{tabular}




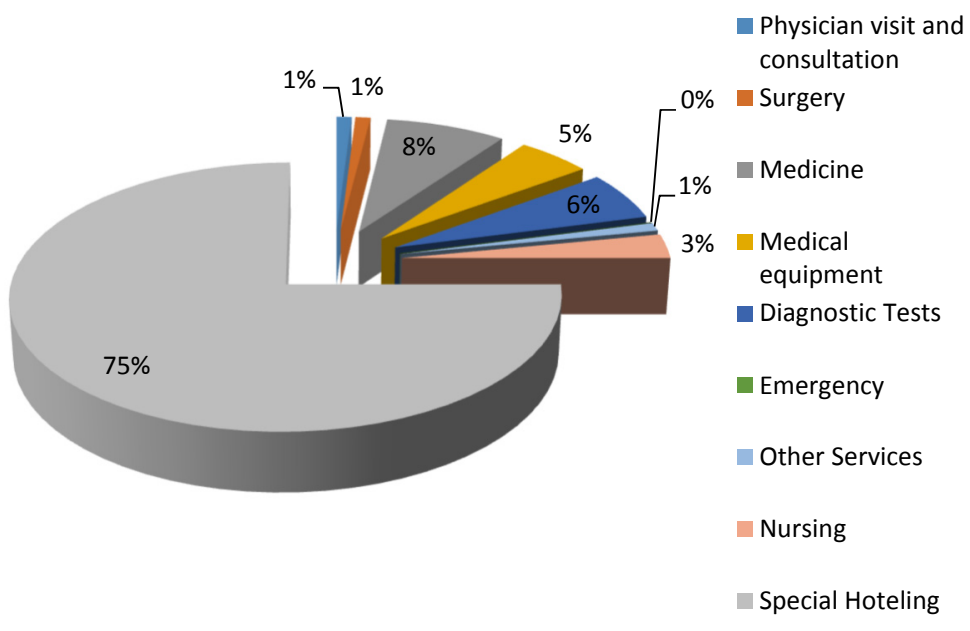

Fig. 1. Proportion of different parts from total direct medical costs for premature or preterm neonates

Table 2. Direct medical costs based on gestational age

\begin{tabular}{lcccccc}
\hline $\begin{array}{l}\text { Gestational Age } \\
\text { (Weeks) }\end{array}$ & $\begin{array}{c}\text { Neonates } \\
\text { (No.) }\end{array}$ & $\begin{array}{c}\text { Cost of Hospitalization } \\
\text { (Total) }\end{array}$ & $\begin{array}{c}\text { \% of } \\
\text { Total } \\
\text { Cost }\end{array}$ & $\begin{array}{c}\text { Cost of hospital- } \\
\text { ization (per } \\
\text { Day) in dollars }\end{array}$ & $\begin{array}{c}\text { Medical Cost per Neo- } \\
\text { nate in public Hospitals } \\
\text { (Mean) in dollars }\end{array}$ & $\begin{array}{c}\text { Medical Cost per Neo- } \\
\text { nate in Private Hospitals } \\
\text { (Mean) in dollars }\end{array}$ \\
\hline $28<$ & 13 & 82274.55 & $\% 44$ & 248.42 & 8465.52 & 19640.01 \\
$28-<32$ & 32 & 135009.10 & $\% 30$ & 166.419 & 4727.35 & 10967.45 \\
$32<37$ & 71 & 180252.26 & $\% 26$ & 139.40 & 2379.67 & 5520.85 \\
Total & 116 & 397535.92 & 100 & 554.24 & 15572.55 & 36128.32 \\
\hline
\end{tabular}

Table 3. Direct non-medical costs in the studied population

\begin{tabular}{lccc}
\hline Direct Non-Medical Costs & Total Cost & Cost per Neonate (Mean) & Percent \\
\hline Cost of item bought by parents & 9476.23 & 43.58 & 20 \\
Cost of feeding and accommodation of parents during the hospitalization & 5055.52 & 81.69 & 38 \\
Cost of transportation & 10588.16 & 112.64 & 42 \\
Total & 25119.92 & 237.91 & 100 \\
\hline
\end{tabular}

those with 32 to 37 weeks had the least direct medical costs (Table 2). The average direct non-medical costs of each neonate was around \$237.91 (US Dollars), from which almost half was due to traveling of the parents and/or entourages during the hospitalization period (Table 3 ).
Results revealed that during hospitalization in NICU, parents lost 35 work days on average. The number of working days that mothers lost was almost two times more than that of the fathers. Indirect cost per neonate is presented in (Table 4). Based on the assessments, the average cost due

Table 3. Direct non-medical costs in the studied population

\begin{tabular}{lccc}
\hline Direct Non-Medical Costs & Total Cost & Cost per Neonate (Mean) & Percent \\
\hline Cost of item bought by parents & 9476.23 & 43.58 & 20 \\
Cost of feeding and accommodation of parents during the hospitalization & 5055.52 & 81.69 & 38 \\
Cost of transportation & 10588.16 & 112.64 & 42 \\
Total & 25119.92 & 237.91 & 100 \\
\hline
\end{tabular}

Table 4. Different parts of indirect costs in the studied population

\begin{tabular}{lcccc}
\hline & Total Days of Absence & Days of Absence per Neonate (Mean) & Total Cost Due to Absence & Cost Due to Absence (Mean) \\
\hline Mother & 2145 & 22 & 18776.68 & 199.75 \\
Father & 1227 & 13 & 22291.30 & 237.14 \\
Total & 3372 & 35 & 41067.99 & 436.89 \\
\hline
\end{tabular}

Table 5. Cost of initial hospitalization per neonate in the private vs. public hospital (mean)

\begin{tabular}{|c|c|c|c|c|c|}
\hline \multicolumn{2}{|c|}{ Type of Cost } & $\begin{array}{c}\text { Cost of All the Stud- } \\
\text { ied Cases }\end{array}$ & $\begin{array}{c}\text { Cost per Neonate in } \\
\text { Public Hospital (Mean) }\end{array}$ & $\begin{array}{c}\text { Cost per Neonate in Private } \\
\text { Hospital (Mean) }\end{array}$ & $\%$ \\
\hline \multirow{2}{*}{$\begin{array}{l}\text { Direct } \\
\text { costs }\end{array}$} & Direct Medical Costs & 397535.92 & 3515.53 & 8156.04 & 86 \\
\hline & Direct Non-Medical Costs & 25119.92 & 237.91 & 551.96 & 5 \\
\hline \multicolumn{2}{|c|}{ Indirect Costs } & 41067.99 & 436.89 & 873.78 & 9 \\
\hline \multicolumn{2}{|c|}{ Total } & 463723.84 & 4190.34 & 9721.59 & 100 \\
\hline
\end{tabular}


Table 6. Direct medical costs of premature and preterm neonates hospitalized in NICU based on different incidences (US Dollars)

\begin{tabular}{|c|c|c|c|c|c|c|c|}
\hline $\begin{array}{l}\text { Number of All } \\
\text { Premature and } \\
\text { Preterm Births } \\
\text { in the Year } \\
1393\end{array}$ & \multicolumn{2}{|c|}{$\begin{array}{l}\text { Estimated of Gestational } \\
\text { Age-specific Number of } \\
\text { Neonates in Iran }\end{array}$} & $\begin{array}{c}\text { Estimated Number of } \\
\text { Premature/Preterm Ne- } \\
\text { onates (Private vs. Pub- } \\
\text { lic) }\end{array}$ & $\begin{array}{l}\text { Direct Medical Cost } \\
\text { of Premature Neo- } \\
\text { nates Based on Ges- } \\
\text { tational Age (Public } \\
\text { vs. Private; Mean) }\end{array}$ & $\begin{array}{l}\text { Direct Medical Cost of } \\
\text { Premature Neonates } \\
\text { Based on Gestational } \\
\text { Age (Public vs. Private) }\end{array}$ & $\begin{array}{c}\text { Total Direct Medical Cost of } \\
\text { Premature Neonates Based } \\
\text { on Gestational Age in the } \\
\text { Year } 1393\end{array}$ & $\begin{array}{c}\text { Total Direct } \\
\text { Medical Cost of } \\
\text { Premature Neo- } \\
\text { nates in Iran }\end{array}$ \\
\hline \multirow{4}{*}{$\begin{array}{l}m \\
\text { ने } \\
\infty \\
\infty \\
\infty\end{array}$} & $28<$ & 4,628 & 3,933 & 8465.52 & 33299050.41 & 46932073.40 & 313476053.06 \\
\hline & & & 694 & 19640.01 & 13633022.99 & & \\
\hline & $28-<32$ & 9,255 & 7,867 & 4727.35 & 37189990.17 & 52416009.67 & \\
\hline & & & 1,388 & 10967.45 & 15226019.50 & & \\
\hline & $32-<37$ & 75,110 & 63,844 & 2379.67 & 151927190.72 & 214127969.98 & \\
\hline & & & 11,267 & 5520.85 & 62200779.26 & & \\
\hline & $28<$ & 6,303 & 5,358 & 8465.52 & 45355751.53 & 63924929.80 & 426977400.16 \\
\hline \multirow{4}{*}{$\stackrel{\frac{n}{\simeq}}{\simeq}$} & & & 945 & 19640.01 & 18569178.27 & & \\
\hline & $28-<33$ & 12,606 & 10,715 & 4727.35 & 50655497.1 & & \\
\hline & & & 1,891 & 10967.45 & 20738956.48 & 71394453.64 & \\
\hline & $32<38$ & 102,305 & 86,960 & 2379.67 & 206935988.48 & 291658016.71 & \\
\hline & & & 15,346 & 5520.85 & 84722028.22 & & \\
\hline \multirow{6}{*}{$\begin{array}{l}\text { ळ̊ } \\
\text { مे }\end{array}$} & $28<$ & 7,899 & 6,714 & 8465.52 & 56838092.39 & & 535071740.62 \\
\hline & & & 1,185 & 19640.01 & 23270183.70 & 80108276.09 & \\
\hline & $28-<34$ & 15,798 & 13,428 & 4727.35 & 63479530.82 & & \\
\hline & & & 2,370 & 10967.45 & 25989266.73 & 89468797.56 & \\
\hline & $32<39$ & 128,205 & 108,974 & 2379.67 & 259324262.86 & & \\
\hline & & & 19,231 & 5520.85 & 106170404.09 & 365494666.95 & \\
\hline
\end{tabular}

Table 7. Estimated costs of premature and preterm neonates hospitalized in NICU based on Rial (Iranian Currency) and US Dollars in 2014

\begin{tabular}{|c|c|c|c|c|c|}
\hline \multirow{2}{*}{\multicolumn{2}{|c|}{ Prevalence of prematurity }} & $(5 \% / 8)$ & $(7 \% / 9)$ & $(9 \% / 9)$ & $\%$ \\
\hline & & $n=88993$ & $n=121215$ & $n=151902$ & \\
\hline \multirow{4}{*}{$\begin{array}{l}\text { Direct } \\
\text { Costs }\end{array}$} & Direct Medical Costs & $10,191,106,485,301$ & $13,881,035,279,356$ & $13,881,035,279,356$ & 84 \\
\hline & & $313,476,053$ & $426,977,400$ & $426,977,400$ & \\
\hline & Direct Non-Medical Costs & $688,323,388,947$ & $937,546,993,485$ & $1,174,898,019,258$ & 6 \\
\hline & & $21,172,667$ & $28,838,726$ & $36,139,588$ & \\
\hline \multirow{2}{*}{\multicolumn{2}{|c|}{ Indirect Costs }} & $1,264,004,066,130$ & $1,721,666,343,150$ & $2,157,526,385,820$ & 10 \\
\hline & & $38,880,470$ & $52,958,054$ & $66,365,007$ & \\
\hline \multirow{2}{*}{\multicolumn{2}{|c|}{ Economic Burden }} & $12,143,433,940,378$ & $16,540,248,615,991$ & $17,213,459,684,434$ & 100 \\
\hline & & 373529189 & $508,774,181$ & $529,481,996$ & \\
\hline
\end{tabular}

to initial hospitalization per neonate in public and private hospitals was $\$ 4190.34$ and $\$ 9721.60$, respectively, of which $86 \%$ was due to direct medical, $5 \%$ to direct nonmedical, and $9 \%$ to indirect expenses (Table 5).

Next, based on the 5.8, 7.9, and 9.9 age-specific percentiles of the nationwide prematurity, the number of age-specific premature and preterm neonates in Iran was estimated to be 88,$993 ; 121,215$; and 151, 902 during 2014 and 2015. Accordingly, we obtained significant differences in direct medical costs for diverse gestational age, among which the most cost was related to the ages younger than 28 weeks, and the least to the age group of 32 to 38 weeks (Table 6).

These data strongly suggest that the economic burden of prematurity was mainly due to direct medical costs during 2014 and 2015, and the age-specific costs were \$373, 529, $189 ; \$ 508,774,181$; and $\$ 529,481,996$ with respect to their nationwide $5.8,7.9$, and 9.9 percentiles of incidences (Table 7).

\section{Discussion}

In this study, we estimated the potential economic burden of initial hospitalization of premature and preterm births in Iran. Our assessment suggests a major economic burden for prematurity in Iran. We found that $86 \%$ of the expenses for prematurity were due to direct medical costs (collectively $\$ 397535.9283$ a year; $\$ 3515.5363$ per affected neonate per year), and this amount was for initial hospitalization only. We estimated a much larger economic burden from prematurity, as it can cause long-term health problems and longlasting financial effects (18). A study in the U.S. has revealed that the average costs of the initial hospitalization for normal births is about \$2061, whereas this goes up to $\$ 26054$ for premature births (11). Kirk by et al. (10)have reported an average cost of $\$ 31000$ per premature neonate of 32 to 37 weeks for initial hospitalization in the U.S. which constitutes $21.6 \%$ of all the costs attributed to NICU; another study has estimated \$30. 527 per neonate of 32 to 34 weeks old. Another study from the U.S. has conceived $\$ 15100$ per neonate on average (9). A report from India (for neonates hospitalized in NICU) estimated this cost as 4.345 per neonate (27), and a study in Turkey has documented the cost of $\$ 4345$ (\$23 215-7 035) (28). One more study from Turkey examined the costs of 211 premature neonates in a 12-month period, and they found that the per day collective hospitalization and per neonate costs were $\$ 4,187$ and $\$ 308$, respectively (29), whereas another study reported the collective cost per neonate as $\$ 7,036$ per day of hospitalization in 2015 (30). In our study, the cost per day per neonate was $\$ 554.2469$.

Regarding the age-related differences in initial hospitalization costs, we split our samples into different age groups: (i) $<28$, (ii) $28-<32$ and (iii) $>32$ weeks of gestation. We 
found that $44 \%$ of the direct medical expenses are due to the first age group (under 28 weeks), while encompassing only $11 \%$ of the cases. Thus, the average per day cost of each neonate of this group would be $\$ 8,076,261$, which is almost twice that of a neonate aged 32 to under 37 weeks $(\$ 4,532,011)$. This is in agreement with the previous data wherein duration and costs of initial hospitalization for premature neonates have negatively been correlated with age and weight at birth $(9,31)$. In 2006, Smith and Pgibbs also demonstrated that for each two weeks increase in gestational age, there would be about $\$ 28,870$ to $\$ 64,021$ (on average) saving for premature newborns under 33 weeks and $\$ 206,000$ for those under 26 weeks (16).

To have a more realistic assessment of the prematurity costs, we also attempted to calculate the direct non-medical expenses including accommodation and feeding of parents as well as clothing and feeding of other children (ie, siblings of the affected one). Tongo et al. have also indicated direct non-medical costs (\$101 - \$1128.1; \$257.2 on Ave.) (32). Furthermore, the absence days of parents (related to prematurity initial hospitalization) were also calculated as indirect costs. As demonstrated in Table 7, indirect costs comprise a major portion of all costs $(10 \%)$ during initial hospitalization. In a study, the parents' average wage loss due to absence from prematurity initial hospitalization was $€ 5,990$ and $€ 8,175$ in the first and second years (following preterm born), respectively (33).

Noticeably, there are variations between the results of these studies, which can be due to various factors including year and geographical region of study, inflation rates in the corresponding countries, salary and benefits, tariff, and costs in the studied region/hospitals. Also, the costs of medicine and other expenses can be affected by the severity of the disease, birth weight, and NICU- or hospital-specific guidelines.

Because we have no information on the real incidence of prematurity at national level in Iran, we only made an estimation based on the statistics issued by WHO, and thus this might have influenced our results. Similar studies in other hospitals and regions of Iran would be helpful in obtaining a more precise statistic from the costs of prematurity. Therefore, this problem should be managed more efficiently for better cost assessment; moreover, preventive programs should also be implemented.

\section{Conclusion}

The economic burden of initial hospitalization in the NICU of premature newborns is estimated to be significant in Iran. We found that $44 \%$ of the direct medical costs belong to the age group younger than 28 weeks of gestation, while encompassing only $11 \%$ of the cases. To reduce these costs, the healthcare policy-makers might implement two strategies: first, improving educational programs, especially for mothers both before and during pregnancy, to attend to pregnancy hygiene and regular screening programs during pregnancy to prevent or reduce the severity of prematurity; second, updating the facilities of NICU sections to provide better services to the patients, and hence, improve their condition, which would substantially affect their long term lifestyle, education, and socioeconomic situation.

\section{Conflict of Interests}

The authors declare that they have no competing interests.

\section{References}

1. Afrakhteh M, Ebrahimi S, Valaei N. Prevalence of preterm delivery and its related factors in females referring to Shohada Tajrish Hospital, 1995-99. Pejouhandeh. 2003.

2. Slattery MM, Morrison JJ. Preterm delivery. The Lancet. 2002;360(9344):1489-97.

3. Hamilton BE, Martin JA, Ventura SJ. Births: preliminary data for 2005 . Natl Vital Stat Rep. 2006;55(11):1-18.

4. Wang ML, Dorer DJ, Fleming MP, Catlin EA. Clinical outcomes of near-term infants. Pediatrics. 2004 Aug;114(2):372-6.

5. Johnston KM, Gooch K, Korol E, Vo P, Eyawo O, Bradt P, et al. The economic burden of prematurity in Canada. BMC pediatrics 2014;14(1):1

6. Petrou S. The economic consequences of preterm birth duringthe first 10 years of life. BJOG 2005;112(s1):10-5.

7. Kinney HC, editor The near-term (late preterm) human brain and risk for periventricular leukomalacia: a review. Seminars in perinatology; 2006: Elsevier.

8. Rice DP. Estimating the cost of illness. Am J Public Health Nations Health. 1967;57(3):424-40.

9. Russell RB, Green NS, Steiner CA, Meikle S, Howse JL, Poschman K, et al. Cost of hospitalization for preterm and low birth weight infants in the United States. J Pediatr. 2007;120(1):e1-e9.

10. Kirkby S, Greenspan JS, Kornhauser M, Schneiderman R. Clinical outcomes and cost of the moderately preterm infant. Adv Neonatal Care. 2007;7(2):80-7.

11. McLaurin KK, Hall CB, Jackson EA, Owens OV, Mahadevia PJ. Persistence of morbidity and cost differences between late-preterm and term infants during the first year of life. J Pediatr. 2009;123(2):653-9.

12. Hintz SR, Bann CM, Ambalavanan N, Cotten CM, Das A, Higgins $\mathrm{RD}$. Predicting time to hospital discharge for extremely preterm infants. J Pediatr. 2010;125(1):e146-e54.

13. Aboutorabi A, Ghiasipour M, Rezapour A, Pourreza A, Asiabar AS Tanoomand A. Factors affecting the informal payments in public and teaching hospitals. Medical journal of the Islamic Republic of Iran. 2016;30:315.

14. Abolhallaje M, Jafari M, Seyedin H, Salehi M. Financial Management Reforms in the Health Sector: A Comparative Study Between Cashbased and Accrual-based Accounting Systems. Iranian Red Crescent Medical Journal. 2014 Oct;16(10).

15. Korvenranta E, Linna M, Häkkinen U, Peltola M, Andersson S, Gissler $\mathrm{M}$, et al. Differences in the length of initial hospital stay in very preterm infants. Acta Paediatr. 2007;96(10):1416-20.

16. Schmitt SK, Sneed L, Phibbs CS. Costs of newborn care in California: a population-based study. J Pediatr. 2006;117(1):154-60.

17. Petrou S, Mehta Z, Hockley C, Cook-Mozaffari P, Henderson J, Goldacre M. The impact of preterm birth on hospital inpatient admissions and costs during the first 5 years of life. J Pediatr. 2003;112(6):1290-7.

18. Zupancic J. A systematic review of costs associated with preterm birth. Preterm birth: Causes, consequences, and prevention, www nap edu/catalog/11622 html. 2007.

19. Blencowe H, Cousens S, Oestergaard MZ, Chou D, Moller A-B, Narwal R, et al. National, regional, and worldwide estimates of preterm birth rates in the year 2010 with time trends since 1990 for selected countries: a systematic analysis and implications. The Lancet. 2012;379(9832):2162-72.

20. Iran's Ministry of Health [Internet]. Tehran: Iran's Ministry of Health 2015. Available from: http://rvu.behdasht.gov.ir/.

21. Ministry of Cooperatives Labour and Social Welfare.[Internet]. Tehran: Ministry of Cooperatives Labour and Social Welfare 2015. Available from: http://www.mcls.gov.ir/fa/lawlist/kar.

22. Beck S, Wojdyla D, Say L, Betran AP, Merialdi M, Requejo JH, et al. The worldwide incidence of preterm birth: a systematic review of maternal mortality and morbidity. Bull World Health Organ. 2010;88(1):31-8

23. Goujani R, Rezaeian M, Manshori A, Sheikh Fathollahi M, Shahraki Ms, Razi S. Survey on seasonal variation in the frequency of preterm 
births in the city of Rafsanjan in 2011-2012. J Nurs Midwifery Shahid Beheshti Univ Med Sci. 2015;25(88):9820-.

24. Mardanian F, Shahzamani S. Frequency of Preterm Delivery and Premature Infants Requiring Intensive Cares at a Referral Hospital in Isfahan, Iran. J Isfahan Med Sch. 2011;28(113).

25. Pourarian S, Vafafar A, Zareh Z. The incidence of prematurity in the Hospital of Shiraz university of medical sciences and health services, 1999. Razi J Med Sci. 2002;9(28):19-25.

26. Reyhani T, Ajam M. The Survey of Divorce Causes of Gonabad City in 1381.2002 .

27. Narang A, Kiran PS, Kumar P. Cost of neonatal intensive care in a tertiary care center. Indian pediatrics. 2005;42(10):989.

28. Akman İ, Cebeci D, Özek E, İmamoğlu S. Effects of perinatal factors on the duration and cost of hospitalisation for preterm infants in a neonatal intensive care unit in Istanbul. Turk J Med Sci. 2002;32(2):159-63

29. Cömert S, Ağzıkuru T, Akin Y, Telatar B, Tan PD, Ergen SG, et al. The Cost Analysis of Preterm Infants from a NICU of a State Hospital in Istanbul. Iran J Pediatr. 2012;22(2):185.

30. Ogata JFM, Fonseca MCM, Miyoshi MH, de Almeida MFB, Guinsburg R. Costs of hospitalization in preterm infants: impact of antenatal steroid therapy. J Pediatr (Rio J). 2015.

31. Ringborg A, Berg J, Norman M, Westgren M, JÖNSSON B. Preterm birth in Sweden: what are the average lengths of hospital stay and the associated inpatient costs? Acta Paediatr. 2006;95(12):1550-5.

32. Tongo O, Orimadegun A, Ajayi S, Akinyinka O. The economic burden of preterm/very low birth weight care in Nigeria. J Trop Pediatr. 2009;55(4):262-4

33. Feldstein P. Health care economics: Cengage Learning; 2011. 